ATTACHMENT STYLES AND FILICIDE BY GENDER

\title{
Child and Adult Attachment Styles Among Individuals Who Have Committed Filicide: The Case for Examining Attachment by Gender
}

\begin{abstract}
Gender differences in self-reported attachment styles of 18 individuals who had committed filicide were examined. Insecure attachment styles (avoidant and/or anxiousambivalent) to primary caregivers were particularly common among males. Almost all experienced insecure romantic attachment. Partial support for insecure attachment continuity (childhood to adulthood), particularly among men, was found. Comparisons with 283 men and women who had committed other homicide types revealed that filicide males were the most common (across offender gender and victim-offender relationship) to hold insecure attachment to maternal caregivers. The role and nature of attachment patterns should be extended beyond the existing research focus on maternal filicide.
\end{abstract}

Keywords: attachment, violence, homicide, filicide, child abuse

Cite:

Eriksson, L., Arnautovska, U., McPhedran, S., Mazrolle, P., \& Wortley, R. (2020). Childhood and Adult Attachment Styles Among Perpetrators of Filicide: The Case for Examining Attachment Across Gender, International Journal of Forensic Mental Health. DOI: $\underline{10.1080 / 14999013.2020 .1821128}$ 


\section{ATTACHMENT STYLES AND FILICIDE BY GENDER}

Scholars have highlighted the need for better recognition of the complex nature of filicide (the killing of a child by a parent), to move filicide research forward and inform a proactive, preventive agenda (Brown \& Tyson, 2014; Sidebotham, 2013; Stroud, 2008). To date, much of the filicide literature has focused on understanding the motivations that underlie filicide offending. The majority of this research examine offender motives and/or common scenarios by drawing inspiration from Resnick's (1969) work on filicide typologies. Research shows differences across gender, with maternal filicides more commonly classified as psychotic, altruistic, or 'unwanted child' and paternal filicides more commonly classified as accidental (lack of intention), retaliatory, or jealousy/rejection of child (e.g., Bourget et al., 2007; Liem \& Koenraadt, 2008; Resnick, 1969; Wilczynski, 1997). Recently, research has also begun exploring whether and how individuals who commit filicide differ from individuals who commit other forms of lethal violence. For example, Eriksson et al. (2014) found that women who had killed their children came from less adverse backgrounds (e.g., unemployment, low levels of education, substance problems) compared with women who had committed other forms of lethal violence, but were more likely to have sought help for mental health issues.

This body of literature has provided valuable insight into the immediate intentions and motivations of those who commit filicide, as well as similarities and differences across gender and/or victim-offender relationship. While elucidating the characteristics of perpetrators at the time of the offence may provide indicators of risk and protective factors for filicide, the underlying influences that potentially drive the more immediate motivations of filicide perpetrators remain unaddressed. Specifically, previous research offers little insight into the intra-psychic dynamics and relationship models which may relate to filicide and be rooted in a perpetrator's childhood experiences (Brown \& Tyson, 2014; Sidebotham, 2013; Stroud, 2008). A better understanding of the potential transference of early attachment relationships to intimate relationships in adulthood offers a unique approach for risk 


\section{ATTACHMENT STYLES AND FILICIDE BY GENDER}

identification within the context of child abuse, especially for those linked with insecure attachment resulting from early experiences of abuse, neglect, or abrupt separation (Stroud, 2008). In turn, such knowledge could provide an additional target for intervention and prevention programs.

Nevertheless, only a handful of recent studies have examined the links between early attachment experiences and filicide (Barone, Bramante, Lionetti, \& Pastore, 2014; Haapasalo \& Petäjä, 1999; McKee \& Egan, 2013). Furthermore, despite calls for the examination of early attachment experiences among fathers who kill their children (Barone et al., 2014), to date studies exploring attachment have, to date, predominantly focused on the theoretical and empirical role of the quality of caregiver attachment relationships among mothers who perpetrate filicide. A lack of empirical evidence on attachment styles of individuals who commit filicide undermines systematic efforts to identify and address any significant experiences in early caregiver relationships that might have intergenerational connotations. Examining the early attachment styles of those who commit filicide alongside the attachment styles to their (present) romantic partners offers a deeper insight into childhood nurturing experiences and quality of the attachment bond in adulthood that may, in turn, improve understanding of specific vulnerabilities that may place a person at high risk for killing their child.

\section{Attachment Theory}

The contemporary conceptualisation of attachment within interpersonal relationships emerges from the theoretical foundations laid by the joint work of Bowlby (1973) and Ainsworth (1978). Bowlby, an ethological psychiatrist, identified that when infants are distressed or alarmed, they will seek contact with caregivers by eliciting a range of innate vocal and expressive signals that promote caregiving and attention. Bowlby theorised that just as infants are expressing innate signalling behaviour, the caregiver response, of attending 


\section{ATTACHMENT STYLES AND FILICIDE BY GENDER}

and caregiving, is also an innate behaviour. 'Attachment' is developed through the repeated signal and response patterns of the infant-caregiver relationship. With stronger attachment linked to greater (in terms of response time and accuracy of signal interpretation) caregiver responsiveness. Infants who experience predictable, timely and accurate responses from their caregiver(s) were observed to display intense emotional stress behaviours when separated from their caregiver(s). It was assumed that reactions to the availability of the attachment figure, predominantly the mother, would have a profound effect on the child and the parentchild relationship. As such, the mother-infant bond, and especially its disruption resulting from prolonged separation, deprivation, or bereavement, is considered to have an important developmental impact (Bretherton, 1992).

Developing this signal/response theory of attachment, Ainsworth (1978) identified that infants display a continuum of behaviours when separated from their primary caregiver that reflect the strength of the signal and response partnership, or attachment, between a caregiver and the infant. Some infants display intense stress/distress signals (e.g., crying, clinging, searching) while others emit no such distress signals. Focusing particularly on parent-infant separation and reunion behaviours, Ainsworth (1979) observed three infant attachment styles: secure attachment, anxious-ambivalent, and anxious-avoidant, with a fourth style identified more recently as disorganised attachment (Main \& Solomon, 1986). Infants displaying secure attachment feel comfortable and safe around their mother and show distress when separated. Upon the mother's return, the infant reacts with positive attachment behaviours such as proximity seeking and smiling before recommencing environmental interaction (exploration and play). In contrast, infants with anxious/ambivalent distrust the reliability of their mother's caregiving and become intensely distressed even prior to their mother's departure. Upon her return, the infant clings to her mother anxiously but is difficult to comfort or calm and does not recommence environmental interaction. Also reflecting an 


\section{ATTACHMENT STYLES AND FILICIDE BY GENDER}

insecure attachment style, but in a more passive way, anxious-avoidant infants show little distress or response to their mother's presence either during separation or reunion and do not engage in proximity seeking behaviours but continue environmental interaction uninterrupted. This attachment style often reflects a caregiver relationship that prioritises and attends to the physical needs of the infant but deprioritises the emotional needs of the child. Finally, disorganised attachment is reflected in the infant's contradicting reactions upon the mother's return, such as simultaneously combining proximity seeking and avoidance behaviours, and is formed when caregiver behaviour is frightening and/or frightened towards the infant.

Bowlby (1973) and Ainsworth (1989) argued that these early attachment patterns become internalised working models of the self and others and, thus, shape a person's close relationships (e.g., those with partners and own children) later in life. Importantly, Bowlby (1973) highlighted that a person's internal working model of attachment tends to be transmitted across generations. For example, securely attached individuals who develop emotional stability, independence and high tolerance for intimacy usually have securely attached parents who display similar interpersonal and caregiving capacities. Insecure attachment styles tend to develop in the context of specific and adverse relational circumstances (Ainsworth, 1979). According to Bowlby (1973), attachment patterns play a key role in "the inheritance of mental health", which should be considered equally important to "genetic inheritance" (p. 323). Given the transmission of a person's predominant attachment style from childhood into adulthood, it may, therefore, be postulated that early insecure attachment styles (such as anxious-ambivalent and anxious-avoidant), which tend to develop in the context of specific, often negative life circumstances, may have a profound impact on a person's way of relating with and behaviour towards other people, including infants and children, as adults. 
ATTACHMENT STYLES AND FILICIDE BY GENDER

\section{Attachment and Female-Perpetrated Filicide}

Early attachment theories have been incorporated into psychoanalytical frameworks of understanding why people commit filicide. Such perspectives place emphasis on understanding an individual's internal conflicts, believed to originate in their early experiences of nurturance and care. The majority of studies examining the childhood experiences of individuals who have committed filicide have focused on mothers (as opposed to fathers). For example, Fraiberg, Adelson, and Shapiro (1975) reported several case studies of mothers who killed or abused their children and in which, through therapy, it became clear that the parents had enacted a repressed trauma experienced in their own childhood through transference of their aggressive feelings towards their abusive or neglectful parents to their own child. More recently, psychoanalytical approaches have also been adopted in the selfpsychology perspective to better understand mothers' motivations within the specific context of filicide. According to the self-psychology perspective the impetus for a parent killing their child lies in their fragile and damaged sense of self, which the parent strives to preserve by exhibiting physical force over their child (Crimmins et al., 1997). This perspective suggests that that filicidal mothers have themselves experienced such an absence or unreliability of basic nurturance by primary carers that they are unable to develop an adequate sense of worth and form nurturing relationships and safe attachments with others as an adult (Crimmins et al., 1997). Furthermore, it is because of such poor formative (early) relationships that when these individuals become parents, the child may represent a threat to the compromised sense of self and thus become worthy of destruction (symbolically representing an abusive parent or unworthy self) (Crimmins et al., 1997).

A small, but growing, body of theoretical literature on motivations for filicide echo the psychodynamic perspective of theories such as attachment theory. For example, in the maternal filicide theoretical framework, Mugavin (2008) proposed that specific 


\section{ATTACHMENT STYLES AND FILICIDE BY GENDER}

vulnerabilities, including history of abuse and inadequate maternal role development, can give rise to warning signs, such as an inability to parent or lack of interest in an unwanted child, which are immediate antecedents of child abuse or filicide perpetrated by women. Specifically, the woman's attachment experience to her primary mother figure is considered critical for the quality of attachment in her own maternal role. Of concern are disturbed attachment relationships, which, in the absence of unresolved early loss or trauma, can result in the intergenerational transmission of inadequate maternal role development and which, in the context of specific (unfavourable) triggers, can result in filicide.

The few empirical studies that have examined the quality of attachment relationships among women who kill their children show support for a focus on attachment processes. In their study of 21 cases of maternal filicide, McKee and Egan (2013) found that while some mothers were found to reject and emotionally detach themselves from their children, others (particularly those who killed their children for 'altruistic' reasons and/or who contemplated/attempted suicide), often experienced low self-reliance on their abilities as maternal caregivers to care (physically and emotionally) for their child. Similarly, Barone et al.'s (2014) study indicated that the intergenerational transmission of at-risk experiences within attachment relationships may influence an increased risk for filicide. Comparing the quality of past attachment experiences to a primary carer between 23 mothers who had committed filicide, 37 mothers with mental illness, and 61 mothers without mental illness, they found that, compared to the other two groups, mothers who had committed filicide were more likely to have insecure/enmeshed attachment styles, displaying an intense focus on the negative emotions and an angry preoccupation with early attachment relationships, but less capacity for consciously reflecting on their attachment conflicts (resulting in the identification with a violent attachment figure). The authors concluded that this made the transmission of their disrupted, early attachment experiences and associated violent 
ATTACHMENT STYLES AND FILICIDE BY GENDER

behaviour more likely (Barone et al., 2014).

Attachment and Male-Perpetrated Filicide?

Studies of the quality of attachment relationships among filicidal fathers are few and far between, despite calls from researchers to address this knowledge gap (Barone et al., 2014). Instead, studies of attachment among men who are violent usually focus on lethal and non-lethal intimate partner violence perpetration (e.g. Dutton, 2002; Genest \& Mathieu, 2014), while very little attention has been given to other forms of male violence within the family, including filicide. A notable exception is Sachmann and Harris Johnson's (2014) qualitative study of long-term biopsychosocial antecedents in nine cases of familicide-suicide (the killing of partner and child/ren, followed by the perpetrator committing suicide). They found that a combination of risk factors is at play, including early adverse (abusive) childhood experiences resulting in attachment disturbances, history of domestic violence, and specific diagnostic profiles in the form of cluster B personality types. The authors argued that screening for high-risk cases should consider the psychodynamic nature of these aspects, which represent discernible vulnerabilities that may place a person at high risk for engaging in such an offence. Specifically, they considered individuals with anxious-avoidant, preoccupied (otherwise known as anxious-ambivalent) or disorganised attachment styles the most vulnerable for violent acting out of their intense abandonment anxiety and rage.

\section{Study Focus}

Given that paternal filicide is as common as maternal filicide (Bourget et al., 2007; Eriksson et al., 2016) and that fathers are typically the most frequent perpetrators in filicide of children in later childhood (Bourget et al., 2007), this reveals an imbalance in current knowledge about filicide, in which most research attention has been given to women despite the equal (or in some instances greater) representation of men as perpetrators. To begin addressing this imbalance and enhance understanding of filicide, it is important to broaden 


\section{ATTACHMENT STYLES AND FILICIDE BY GENDER}

knowledge on the psychological processes-specifically attachment-related dynamics-among both men and women who kill their children.

Thus, the aim of the current study was to examine child and adult attachment styles of women and men who kill their children and to identify potential preventive actions in families with higher risk for filicide. We used in-depth data with 18 women and men convicted of killing their child ('filicide') and 283 women and men convicted of a homicide other than filicide ('non-filicide homicide'). We focused on six main areas: 1) attachment styles to primary caregivers in childhood; 2) developmental contexts (abuse and neglect) in which various forms of child attachment appear; 3) associations between insecure attachment in childhood and perpetration of non-lethal past abuse toward the victim(s) killed; 4) attachment styles to romantic partners; 5) continuity of insecure attachment from childhood to adulthood; and 6) perceived social support and mental health assessment/treatment in the year leading up to the homicide. Importantly, we analysed these patterns across gender of the respondent. In addition, to determine if the findings related to attachment, childhood abuse and neglect, etc. were specific to individuals who committed filicide, we compared them to individuals who committed non-filicide homicide.

Given limited existing research, our hypotheses are exploratory only. We expect to see associations between insecure attachment to caregivers and experiences of adverse childhood experiences as well as perpetration of non-lethal child abuse. We also expect to see continuity of insecure attachment styles from childhood to adulthood, and relatively low levels of social support and mental health assessment/treatment in adulthood. We expect these patterns will be present across gender for both the filicide and non-filicide homicide subsamples, though perhaps more pronounced for the filicide group.

\section{Method}

\section{Research Design}




\section{ATTACHMENT STYLES AND FILICIDE BY GENDER}

The data were drawn from the Australian Homicide Project, which examined the causes of homicide to improve understanding of pathways to homicide within the context of interventions by criminal justice, health and social welfare agencies. The Australian Homicide Project involved comprehensive face-to-face interviews conducted between 2009 and 2013 with 302 individuals convicted of murder or manslaughter (identifying reference). The full dataset contained information about individuals who have killed intimate partners, family members (including children), friends, and strangers. Given the focus of the current paper, we split the sample into filicide and non-filicide homicide (see "Sample" below). The Australian Homicide Project data included both quantitative and qualitative measures. For the current study we used a mixed-methods approach, whereby we examined trends and patterns in experiences in childhood and adulthood, and used qualitative data to augment these quantitative results.

\section{Data Collection Procedures}

The project was approved by the [identifying information] Human Research Ethics

Committee. The data collection procedures were the same for all respondents, irrespective of their relationship with the victim they killed (i.e., filicide vs. non-filicide homicide). Correctional officers provided eligible individuals with introduction packages a few weeks before data collection was due to commence. These contained information sheets stating the structure and aim of the research, as well as expression of interest (EOI) forms. Individuals interested in the project put their EOIs into a sealed envelope. They then had the choice of either returning the envelopes to the correctional officers who forwarded the sealed envelopes to the research team, or mailing the envelopes directly to the research team (postage prepaid). Before data collection commenced, a one-day training workshop was held with the team of interviewers hired specifically for the project. The interview team consisted of five interviewers with experience conducting interviews and/or working with correctional clients. 


\section{ATTACHMENT STYLES AND FILICIDE BY GENDER}

The workshop provided interviewers with detailed information about the data collection process, including safety procedures at correctional centres and managing participant distress.

The interviews were conducted through face-to-face interviews at custodial and community corrections facilities across Australia. Only those individuals who had expressed an interest in the project via the EOI process (described above) were invited to participate in the interviews. The vast majority of interviews were conducted in designated interview rooms within the facilities. Some of the interviews at the custodial locations were conducted within visitation areas. In these instances, the interviewer and respondent were physically distanced from other individuals to ensure the interviews were not overheard. Prior to commencement of the interview, participants were provided with an information sheet detailing of the study's purpose and procedure. Interviewers were instructed to read the information sheet to any participants who displayed difficulties with reading. Participants were encouraged to ask questions about the interview and the nature of the study. Importantly, the interviewers made it clear to participants that some questions might be distressing, that their participation was voluntary, and that they had a right to withdraw their participation at any time without explanation. Those who wanted to proceed were provided with a consent form to sign.

During the interview, the interviewer read questions to the respondent and recorded their responses onto an interview schedule. The interview schedule included a range of selfreport measures to examine individual (e.g., socio-demographics), developmental (e.g., childhood experiences) and situational (e.g., victim-offender relationship) characteristics of homicide. The variables relevant to the current study are described further below. ${ }^{\mathrm{i}}$ The interviews lasted approximately 1.5-2 hours. Given the sensitive topic, a few of the respondents showed minor distress, most commonly because of feelings of remorse. Actions taken by interviewers included skipping sections of the interview and, on limited occasions, notifying the prison psychologist (without revealing the trigger of the distress). Of the 


\section{ATTACHMENT STYLES AND FILICIDE BY GENDER}

interviews conducted within custodial facilities, some were interrupted due to roll call/head count procedures and resumed shortly thereafter. Other reasons for interruptions included lunch breaks, toilet visits, and cigarette breaks. We did not provide snacks and/or drinks to the respondents during the interviews. A modest amount of remuneration (AUD10 in custodial corrections and AUD20 in community corrections) was provided to respondents to compensate for their time in jurisdictions that allowed for it. Reimbursement was provided directly to participants (community interviews) or through internal money transfer (custodial interviews).

\section{Sample}

The full dataset included a range of victim-offender relationships (i.e., intimate partners, family members, friends, strangers). Given the focus of the current paper, we split the sample into filicide and non-filicide homicide. The filicide sub-sample included those respondents who had killed their own child. Following extant literature (e.g., Liem \& Koenraadt, 2008), we included both individuals who had killed their genetic kin and those who had killed a stepchild. We excluded one male who had committed filicide from the analyses due to extensive missing data, resulting in a total sample of 18 respondents in the filicide sub-sample. The non-filicide homicide sub-sample consisted of 283 respondents who had killed someone other than a genetic child or stepchild.

Of the 18 respondents in the filicide sub-sample, 5 were female and 13 were male. At the time of the interview, they were on average 46.5 years of age $(S D=11.9)$, and at the time of the incident, they were on average 33.7 years of age $(S D=9.9)$. Two of the respondents in the filicide sub-sample identified themselves as Aboriginal or Torres Strait Islanders. Only one-third of respondents in the filicide sub-sample reported that they had completed high school (or higher) at the time of the filicide. All of the women had killed biological children, none had killed an intimate partner in conjunction with the filicide (i.e., committed 


\section{ATTACHMENT STYLES AND FILICIDE BY GENDER}

familicide) and all except one had killed one child (see Table 1). In contrast, eight of the men reported killing stepchildren and five of the men also killed their intimate partner (i.e., committed familicide; see Table 1). Most of the men had killed one child (see Table 1). Four respondents reported that other people were also involved in the filicide. Of the 21 filicide victims, 9 were male and 10 were female, while gender was unknown for 2 victims (i.e., information was not provided by the respondent; see Table 1).

Of the 283 respondents in the non-filicide homicide sub-sample, 35 were female and 248 were male. They were on average 42.4 years of age $(S D=12.1)$ at the time of the interview and 30.5 years of age $(S D=10.5)$ at the time of the homicide. The non-filicide homicide subsample was similar to the filicide subsample in its proportion of respondents who identified themselves as Aboriginal or Torres Strait Islanders (13\%) and who had completed high school (or higher; 33\%). Of the non-filicide homicide respondents, 27 percent had killed an intimate partner, 36 percent had killed an acquaintance/friend, 30 percent had killed a stranger, and 7 percent had killed a family member (other than their child/ren). Approximately one-third (32\%) reports that other people were also involved in the homicide.

\section{Measures}

\section{Child Attachment to Primary Caregivers}

Attachment styles to maternal and paternal caregivers in childhood were assessed using the brief self-report Parental Caregiving Style Questionnaire (Hazan \& Shaver, 1987). Respondents were provided with three descriptions of 'parental caregiving styles', each of which was measured on a seven-point Likert response scale of 1 (Not at all like my caregiver) and 7 (Very much like my caregiver). The three descriptions correspond with Ainsworth's (1978) original childhood attachment styles: 1) warm/responsive (secure), 2) cold/rejecting (avoidant), and 3) ambivalent/inconsistent (anxious-ambivalent). Respondents 


\section{ATTACHMENT STYLES AND FILICIDE BY GENDER}

were first asked about their mother's caregiving style (i.e., provided with the three descriptions and asked the extent to which each applied to their mother) and then their father's caregiving style (same process only this time respondents were asked about their father). Respondents were asked about alternative caregivers if mother/father was absent. As per Cowan and Cowan (2007), we did not combine the attachment styles to maternal and paternal caregivers into one overall working model but, rather, presented them separately. The measure demonstrates good reliability and validity, for example as demonstrated by Collins and Read (1990) who found an association between responses on the Parental Caregiving Style Questionnaire and people's working models of self and feelings of security in adulthood. While most of the respondents were able to be classified into one of the three attachment styles, some respondents (only males) reported equally high scores on two of the attachment styles. We therefore created an additional category labelled 'mixed attachment pattern' (where the respondent scored equally on two of the styles, e.g., avoidant and anxious-ambivalent). In addition, some respondents reported an absence of either a maternal or paternal caregiver (biological and alternative). In other words, some respondents reported only having one caregiver. These respondents only completed the Parental Caregiving Style Questionnaire for the relevant caregiver (maternal or paternal), with the other caregiver classified as 'absent'. In addition to examining specific attachment styles, we also dichotomised the variables into secure and insecure, where insecure incorporates avoidant and anxious-ambivalent. Those respondents who reported equally high scores on secure and any of the insecure categories (i.e., avoidant and/or anxious-ambivalent) were classified as insecure.

Experiences of Abuse and Neglect in Childhood

Abusive and neglectful experiences in childhood were measured using several items from a scale examining family violence (Stewart, Senger, Kallen, \& Scheurer, 1987). We did 


\section{ATTACHMENT STYLES AND FILICIDE BY GENDER}

not summate the full scale to create a total score. Instead, we examined the questions separately to assess various forms of abuse and neglect in childhood. All items were selfreported. Three questions asked about direct experiences of physical abuse (e.g. "My parents have beaten me so badly that I was ashamed to be seen by others"). Similar to Stewart et al.'s (1987) study, which revealed high correlations between the physical abuse items, the Cronbach's alpha for the three items in the current study was .892. We dichotomized this scale such that those who responded positively to any of the three questions were coded as having direct experiences of physical abuse. Two questions asked about exposure to interparental violence. As research shows the importance of examining the gender directionality of inter-parental violence (e.g. Eriksson \& Mazerolle, 2015), we measured father-to-mother violence ("There were times when my father beat my mother") and mother-to-father violence ("There were times when my mother beat my father") separately. As expected, the inter-item correlation for these two variables in the current study was low $(r=.249)$, which confirms our choice to examine these variables separately. In addition, one question asked about physical neglect ("While I was growing up my parents neglected my physical needs") and one question asked about emotional neglect ("While I was growing up my parents neglected me emotionally"). The inter-item correlation for these two variables in the current sample was

relatively high $(r=.672)$. All items were originally measured using a Likert scale ranging from 1 (Never) to 5 (Very often), but were dichotomised such that 'never' indicated 'no exposure to abuse/neglect' and all other responses (e.g., 'sometimes') indicated 'exposure to abuse/neglect'.

Perpetration of Past Non-Lethal Child Abuse

Self-reported child abuse perpetration was measured by a question ascertaining child discipline behaviours directed toward any child(ren) living in the household. Respondents were presented with a statement ("I spanked, or hit the child across the bottom") and asked to 


\section{ATTACHMENT STYLES AND FILICIDE BY GENDER}

indicate how often (between 1 'Never' and 5 'Very often') they had engaged in that behaviour in the year leading up to the homicide. The responses were dichotomised such that 'Never' indicated 'no perpetration of abuse' and all other responses (e.g., 'Sometimes') indicated 'perpetration of abuse'.

\section{Adult Romantic Attachment}

Attachment styles to romantic partners in adulthood were measured using the 36-item self-report Experiences in Close Relationships scale (Brennan, Clark, \& Shaver, 1998). The scale includes two dimensions. The first dimension is the 'model of self', which measures the respondent's subjective degree of self-worth and their dependency/anxiety for approval from romantic partners. The second dimension is the 'model of others', which measures the extent to which respondents avoid closeness in romantic relationships. Based on these two dimensions, the scale classifies respondents into one of four attachment styles: secure (positive model of self and others), preoccupied (anxious model of self; positive model of others), dismissing (positive model of self; avoidant model of others), and fearful (anxious model of self; avoidant model of others). Attachment scholars frequently use this scale and it displays good reliability and validity (Ravitz, Maunder, Hunter, Sthankiya, \& Lancee, 2010). In the current study, Cronbach's alpha for this 36-item scale was .813.

\section{Social Support and Mental Health}

We measured participants' self-reported perception of social support in the year leading up to the homicide by asking: "During this time, did you ever feel all on your own and that you had no one to turn to". While not a direct measure of help-seeking, this measure captures those individuals who may have needed informal or formal social support and/or contact with mental health services. We measured mental health treatment/assessment by asking respondents whether they had received treatment or assessment for a mental health issue in the year prior the homicide. 


\section{ATTACHMENT STYLES AND FILICIDE BY GENDER}

\section{Analytical Strategy}

We extracted information about the respondents' childhood (attachment styles to primary caregiver and experiences of abuse and neglect in childhood) and adulthood (romantic attachment, perpetration of non-lethal violence toward children, social support and mental health). We present a detailed overview of the filicide subsample in Table 1, listing all variables examined in the current study. In the results section we highlight trends and patterns observed in the data across gender of the perpetrator and type of homicide (filicide vs. nonfilicide homicide). Because of the relatively small sample of filicide perpetrators, we only provided descriptive comparisons rather than inferential statistics. Thus, our analyses are restricted to the presentation of prevalence rates (valid \%; Tables 2-4), and results pertaining to the filicide perpetrators are presented as case studies. Qualitative data collected from the filicide subsample during the interviews are also presented to further illustrate the results. The case study approach applied to the filicide subsample enables researchers to examine childhood and adulthood experiences within each individual case, as well as gain an indicator of consistencies and differences that may emerge between those cases (Yin, 2003). We chose this methodology due to the varied and oftentimes complex nature of filicide cases (Farooque, \& Ernst, 2003). Because of the small numbers of filicide perpetrators, caution must be exercised in interpreting the data.

\section{[Table 1 near here]}

\section{Results}

\section{Attachment Styles to Primary Caregivers in Childhood}

As seen in Table 2, three of the five women who had killed their child were classified as having a secure attachment to their maternal and paternal caregivers (as measured by the 'Parental Caregiving Style Questionnaire'; see Method). The other two women had anxiousambivalent and avoidant attachment styles to both caregivers (see Table 1). None of the 


\section{ATTACHMENT STYLES AND FILICIDE BY GENDER}

women reported an absent caregiver. Among the male respondents, secure attachments were more common for the maternal caregiver than the paternal caregiver (see Table 2). The most commonly observed attachment style between the male respondents and their maternal caregivers was anxious-ambivalent, with over half of the men having this style in some form (either separately or as a mixed attachment pattern, e.g. ambivalent/avoidant, see Table 1). None of the men reported an absence of a maternal caregiver, while three reported an absent

male caregiver. As one of the men stated when asked about his father: "[I] don't know who he was" (case \#15). Insecure attachment to caregivers was also a common feature among those who had committed non-filicide homicide (see Table 2). Here the prevalence was similar across both groups (filicide and non-filicide homicide). The main exception was observed for the males in the non-filicide homicide group, where the prevalence rate of insecure maternal attachment was approximately half that of males who had committed filicide.

[Table 2 near here]

\section{Experiences of Abuse and Neglect in Childhood}

All of the female and nearly all of the male respondents who had committed filicide were exposed to some form of abuse or neglect during their childhood (see Table 1), though the nature of the abuse/neglect differed across gender (see Table 2). While none of the females reported physical abuse by their parents, nearly half of the male respondents reported this form of abuse. The most common form of inter-parental violence was observing their father abusing their mother. Providing contextual information about his violent father, one man said in the interview: "Dad was a drinker. Mum was always leaving [him]." (case \#18). Much less common was mother-to-father violence. Three of the women and almost all of the men reported having experienced emotional neglect, which was more common than physical neglect. Differences were further observed across filicide and non-filicide homicide. In particular, females who had committed non-filicide homicide more commonly reported 


\section{ATTACHMENT STYLES AND FILICIDE BY GENDER}

exposure to abuse and neglect in childhood compared with females who had committed filicide.

We then examined whether the respondents' attachment to their caregivers (classified as secure or insecure) developed concurrently with abusive experiences (directly, or indirectly by observing inter-parental violence). Table 3 reveals that among the men in the filicide group who had been exposed to abuse, very few were classified as having a secure attachment style to both parents (or only to the maternal caregiver, in the case of absent paternal caregivers). Instead, the majority of men who experienced some form of abuse had insecure attachment to at least one of their caregivers, though this was also common among those men who did not report exposure to abuse. In contrast, two females who had committed filicide had secure attachment styles despite abusive experiences. The responses from the non-filicide homicide group revealed that the majority of the males and females with insecure attachment to caregiver(s) had grown up experiencing abusive in childhood.

[Table 3 near here]

Table 3 further shows the overlap between experiences of physical and/or emotional neglect and attachment style in childhood. The majority of both men and women in the filicide group who reported neglectful experiences also had insecure attachment to at least one of their caregivers (or only the maternal caregiver, in the case of absent paternal caregivers). These similar patterns were observed for the non-filicide homicide group. In contrast, all of the women and men in the filicide group who reported an absence of neglectful experiences formed secure attachments to their caregivers. This was not always the case for the non-filicide homicide group.

\section{Past Abuse Toward Children in Household}

A higher proportion of those who had committed filicide reported perpetrating child abuse in the year prior to the filicide incident compared with those who had committed non- 


\section{ATTACHMENT STYLES AND FILICIDE BY GENDER}

filicide homicide (see Table 3). An association between insecure attachment in childhood (to at least one caregiver) and the perpetration of past non-lethal abuse toward their child(ren) was observed for the female respondents in the filicide group. For the males, no such association was observed. Instead, an equal proportion of the men with insecure attachment in childhood had committed child abuse as had not committed child abuse. Similarly, no association between insecure attachment in childhood and child abuse perpetration was observed for the males and females who had committed non-filicide homicide.

\section{Adult Romantic Attachment}

The majority of both the female and male respondents who had committed filicide were classified as having insecure attachment styles to their romantic partners (as measured by the 'Experiences in Close Relationships' scale; see Method). Only one-fifth of women and a quarter of the men reported a secure attachment style (see Table 4). For women, insecure attachment styles included dismissing and preoccupied, while for men, the most frequent attachment style was fearful. As one male respondent with fearful romantic attachment stated when confronted with the romantic attachment scale questions: "That was my problem [...] [I] didn't open up to anyone" (case \#6). This comment exemplifies how uncomfortable fearfully attached individuals often feel with close reliance on other people. The majority of respondents who had committed non-filicide homicide were also classified as having insecure attachment in romantic relationships, most commonly 'preoccupied'.

[Table 4 near here]

\section{Continuity of Attachment (Childhood $\rightarrow$ Adulthood)}

In terms of continuity, a large proportion of those with insecure attachment styles to at least one caregiver in childhood also had insecure attachment to romantic partners in adulthood (see Table 4). This was common both for respondents who had committed filicide and those who had committed non-filicide homicide. Conversely, continuity was seldom 


\section{ATTACHMENT STYLES AND FILICIDE BY GENDER}

observed for secure attachment styles. This was particularly prominent for the women who had committed filicide, where two of the three respondents who reported secure attachment to at least one caregiver in childhood had developed insecure (specifically dismissing, see Table 1) attachment to romantic partners in adulthood. Conversely, a discontinuation of insecure attachment style was uncommon within the sample. Only one of the respondents who had committed filicide (a male) experienced a discontinuation of an insecure attachment style. The highest prevalence of discontinuation was reported by non-filicide homicide males, where one-fifth of respondents reported insecure attachment to primary caregivers and secure romantic attachment in adulthood.

\section{Social Support and Mental Health}

The majority of respondents across both the filicide and the non-filicide homicide groups reported feeling all on their own and with nobody to turn to in the year leading up to the homicide (see Table 4). This was a particularly prevalent experience for women. Nevertheless, while many disclosed a perceived lack of social support, very few had actually received assessment or treatment for a mental health concern (see Table 4). As one female respondent who had committed filicide noted: "I was depressed, but didn't know, didn't realise. No one picked it up." (case \#2). In fact, none of the males who had committed filicide had received treatment or assessment for a mental health concern, despite over half reporting a lack of social support.

\section{Discussion}

This study contributes to deepening current understanding of filicide and expanding the knowledge base around the complexities underlying this tragic event (Brown \& Tyson, 2014; Sidebotham, 2013; Stroud, 2008), and responds to suggestions that attachment experiences are important to investigate (Stroud, 2008). Understanding the quality of early attachment experiences of individuals who commit filicide can illuminate the psychological 


\section{ATTACHMENT STYLES AND FILICIDE BY GENDER}

reasoning that may be driving their violent actions in adulthood. While much existing filicide literature explores the more immediate motivations and/or common scenarios of individuals who kill their children (e.g., Bourget et al., 2007; Eriksson et al., 2014; Liem \& Koenraadt, 2008; Resnick, 1969; Wilczynski, 1997), the current study explores the more long-term antecedents associated with filicide perpetration.

The focus on attachment across gender in the current study is particularly noteworthy given that past research is predominantly about mothers, whereas it has less to say about fathers' experiences. This study examined gender similarities and differences across six areas: 1) attachment styles to primary caregivers in childhood; 2) developmental contexts (abuse and neglect) in which various forms of childhood attachment appear; 3) association between insecure attachment in childhood and the perpetration of non-lethal child abuse; 4) attachment styles to romantic partners; 5) the potential continuity of insecure attachment from childhood to adulthood; and 6) perceived social support and mental health treatment/assessment. In addition, to determine if the findings were specific to individuals who committed filicide, we compared them to individuals who committed non-filicide homicide. Such potential differences are important to explore, given research that suggests the distinctiveness of offender characteristics across different victim-offender relationships (see e.g., Caman et al., 2016; Dobash \& Dobash, 2015; Eriksson et al., 2016).

The current study revealed that those who reported the greatest extent of insecure attachment styles (anxious-ambivalent and/or avoidant) to their caregivers in childhood were males who had committed filicide, followed by non-filicide perpetrators. This means that the childhood experiences of men who kill their children were more often characterised by worries about whether their parents really cared for them, whether their parents might abandon them, and doubts on whether they can really count on their parents' help in times of need. Such lack of trust in a primary caregiver is the basis of an anxious-ambivalent and 


\section{ATTACHMENT STYLES AND FILICIDE BY GENDER}

avoidant attachment style, and is also likely to be reflected in adult relationships (Harris Johnson, 2009). The limited literature available reveals similar findings, with early development of attachment disturbances seen as a key factor involved in male-perpetrated familicide-suicide (Sachmann \& Harris Johnson, 2014). This provides preliminary support for our argument that the role and nature of attachment patterns should be extended beyond the focus on maternal filicide that is so prevalent in much of the research to date. In fact, the females in the filicide subsample reported the highest prevalence rates of secure attachment to primary caregivers, even at the same rate as 'normative' Western populations $(60 \%$; van Ijzendoorn, Schuengel, \& Bakermans-Kranenburg, 1999).

The majority of everyone within the sample (both filicide and non-filicide homicide) experienced some type of abuse or neglect during childhood, including having observed abuse between their caregivers. These findings corroborate previous filicide research demonstrating that individuals who commit filicide often grow up in dysfunctional and abusive homes (Eriksson, et al., 2016; Wilczynski, 1997). However, our findings further suggest that an overlap between negative experiences in childhood and the development of insecure attachment to primary caregivers is particularly characteristic for the male filicide respondents and the non-filicide subsample. Cumulatively, these findings imply that the quality of attachment towards primary caregivers in childhood may need to be assessed in combination with exposure to abuse, whether experienced or observed, as well as neglect. Interestingly, however, only the females in the filicide subsample displayed a clear association between insecure attachment to parents in childhood and being the perpetrators of non-lethal abuse toward the subsequent filicide victim(s) in the year leading up to the filicide. Such findings are consistent with Korbin's (1987) qualitative study of mothers who had committed filicide, which found non-lethal abuse to be a response pattern to fears of rejection. In the current study, such clear associations were not observed for the non-filicide 


\section{ATTACHMENT STYLES AND FILICIDE BY GENDER}

subsample or the males who had committed filicide.

Nevertheless, it must be noted that early experiences of abuse and neglect do not necessarily lead to the development of insecure attachment. For example, one man and three women in the filicide subsample who reported experiences of abuse in childhood also reported developing secure attachment styles to their caregivers. This finding stands in contrast to what is expected based on theory and prior research (Raby, Steele, Carlson \& Sroufe, 2015). It may, therefore, be important to examine more information about contextual characteristics of those individuals' upbringings, to investigate further why the experience of abuse or neglect in these cases was not associated with attachment disturbance. It is currently unknown, for instance, whether these individuals might have been placed in foster care or whether they might have had other people in their lives who buffered the potential negative impact of abuse or neglect. In addition, it may be important to determine the exact age at which the abuse/neglect occurred, as well as its frequency and intensity, since early attachment disruptions during the critical developmental time may play a role in the development of brain areas involved in the control of aggressive impulses and behaviour (Dutton, 2002). These are details that would be valuable to obtain information about and we encourage scholars to pursue these lines of enquiry.

Based on attachment theory, one would expect some continuity of insecure attachment from childhood to adulthood. Both Bowlby (1973) and Ainsworth (1989) noted that early attachment experiences shape a person's close relationships later in life. Continuity in attachment styles has been found in other studies of filicide (Mugavin, 2008) and nonfilicide homicide populations (Raby et al., 2015). Yet our findings only provide partial support for the continuity hypothesis. While the majority of respondents across the full sample who reported insecure attachment to one (or both) primary caregiver in childhood also reported insecure attachment in adult romantic relationships, some did not follow this 


\section{ATTACHMENT STYLES AND FILICIDE BY GENDER}

general pattern. For example, one of the men in the filicide subsample who reported insecure attachment to both his caregivers in childhood developed a secure attachment style in romantic relationships. Similarly, two of the women in the filicide subsample who reported secure attachment to both parents in childhood developed dismissing attachment styles to romantic partners. Further studies should, therefore, address the distinct experiences of those who commit filicide that, despite a secure attachment in their childhood, lead them to form insecure attachments in their adulthood; or, conversely, the potential protective factors that may play a role in forming secure attachments in a person's adulthood, despite their insecure attachments in the childhood. Previous research has suggested that higher quality social support during adulthood may be one way to facilitate changes from insecure to secure attachment relationships (Raby et al., 2015).

In the current sample, very few respondents had received treatment/assessment for a mental health issue, and the majority of respondents across gender (and homicide type) reported experiencing low social support. Attachment theory posits that early childhood experiences influence how we relate to other people later in life (Ainsworth, 1978; Bowlby, 1973) and there is some research to indicate that being uncomfortable with closeness and attachment to other people may hinder help-seeking behaviour (Vogel \& Wei, 2005). As suggested by Fraiberg et al. (1975), the key to ending the cycle of dysfunctional parenting is through accessing and acknowledging painful childhood memories rather than repressing them. It is therefore important to understand the potential intrinsic factors aspects associated with help seeking and willingness to accept support.

\section{Strengths and Limitations}

A major strength of this study was the use of interviews with individuals convicted of killing their children in combination with well-established scales with high psychometric properties. Relative to filicide studies that rely on official data sources (e.g., police and 


\section{ATTACHMENT STYLES AND FILICIDE BY GENDER}

coroners reports; McKee \& Egan, 2013), this methodological approach allows for a more indepth examination of the complex nature of filicide. Importantly, this study addresses an important research gap in the study of attachment, namely the (lack of) examination of attachment processes among fathers who kill their children. The handful of existing studies examining links between early attachment experiences and filicide focus mainly on mothers as perpetrators (Barone et al., 2014; Haapasalo \& Petäjä, 1999; McKee \& Egan, 2013). This is despite calls for studies to examine attachment among men who commit filicide (Barone et al., 2014). Importantly, investigating attachment styles of both males and females who kill their children and how these may relate to their childhood nurturing experiences may broaden understanding of specific vulnerabilities that may increase the risk of killing one's own child.

Nonetheless, some challenges should be acknowledged. Importantly, similar to other filicide studies, our sample is relatively small. This is partly an indication of the low prevalence rate of filicide in the population, but also a result of the choice of methodology. Much of the existing research on filicide utilizes secondary data, such as police files, coronial findings and media reports. However, while the use of such sources may result in larger sample sizes, they provide limited contextualized information. Face-to-face interviews offer insights into the personal histories of individuals who commit filicide that secondary data may not be able to provide, such as childhood experiences, individual internal dynamics and relationship models. Nevertheless, caution must be exercised in interpreting the results given the relatively small sample size. The findings herein are tentative and future research should replicate this study using a larger sample. In addition, our study design did not include a specific comparison group (e.g., parents without a history of abusing their children), which would provide information about the relative frequency of specific attachment styles, particularly the insecure types, and their continuity from childhood to adulthood as well as help-seeking behaviours. 


\section{ATTACHMENT STYLES AND FILICIDE BY GENDER}

Furthermore, the current sample does not constitute a complete representation of the full population of filicide offenders. For example, for obvious reasons our interview data only include non-suicide cases, and past research shows that approximately ten to 50 per cent of those who kill their children commit suicide post-filicide (Benítez-Borrego et al., 2013; Liem and Koenraadt, 2008; Wilczynski, 1997). Similarly, mental health issues are less common among correctional populations compared to, for example, psychiatric populations (Bourget et al., 2007). In addition, the 'dark figure' of filicide may be higher among cases involving young victims ( $<12$ months) compared with older victims, partly due to the difficulties with distinguishing homicide from Sudden Infant Death Syndrome (SIDS) (Brookman \& Nolan, 2006).

In terms of measurement, our data unfortunately do not distinguish who perpetrated the abuse/neglect in childhood (whether mothers, fathers, or both). This needs to be untangled further, as one might expect insecure attachment styles to develop with the abusive and/or neglectful parent but not necessarily with the other parent. In addition, it is wellestablished that multiple-item behavioural-based measures provide more reliable estimates of the prevalence of child neglect compared with the types of single-item self-appraisal measures used in the current study (e.g., Mathews et al., 2020; Straus \& Kantor, 2005). Finally, scoring the measure of attachment in childhood proved difficult, as some of the respondents (only males) reported equal scores on two attachment styles. This highlights one of the limitations of measuring attachment as a taxonomy, whereby respondents are classified into distinct categories, as opposed to a dimensional approach where attachment as a construct is measured on a continuum (see for example Cowan \& Cowan, 2007).

\section{Prevention and Policy Implications}

While the current study adds important information about the attachment styles of women and men who commit filicide, the complex picture portrayed by the analysed cases 


\section{ATTACHMENT STYLES AND FILICIDE BY GENDER}

indicates the need for further research on attachment in the context of filicide. This is particularly relevant given the limited generalizability of the current study. Nevertheless, based on the findings of the current study, it may be important for practitioners (e.g., child welfare support workers) to explore the nature of attachment in a person's relationships, both with their primary caregivers in childhood and intimate partners in adulthood. This information may inform risk assessment for extreme forms of violent behaviour that may lead to fatal outcomes in children.

Because of the well-documented link between insecure attachment styles (i.e., anxious-ambivalent and avoidant) and maternal filicide (Bourget et al., 2007), as well as maternal perpetrators often reporting the feeling of being rejected by their child (Korbin, 1987), it may be useful, for prevention purposes, to better understand and investigate in more detail insecure attachment experiences in mothers who confess to having such feelings, including the feeling of shame, which may arise with destructive impulses. It is important to note, however, that clinicians may also be resistant to acknowledging parents' filicidal drives (Fraiberg et al., 1975). An assessment of early attachment formation in combination with the experience of abuse and neglect may, therefore, present the first step in the direction towards exploring possible filicidal ideations.

Of course, insecure attachment may not be specific to individuals who commit filicide, which is why it is important to compare this form of lethal violence to other forms. In the current study, many of those who had committed non-filicide homicide displayed similarities to the filicide group in terms of their levels of adverse childhood experiences, continuations of insecure attachment from childhood into adulthood, and low levels of social support as adults. Nevertheless, some key differentiating factors between the subsamples were discernible. For example, insecure attachment in childhood was most commonly reported by men who had committed filicide. Further, women who had committed filicide 


\section{ATTACHMENT STYLES AND FILICIDE BY GENDER}

displayed the strongest association between insecure attachment and the perpetration of nonlethal child abuse against their child(ren). These findings provide preliminary support for increased attention given to experiences of early bonding experiences with caregivers for mothers and fathers who come to the attention of services regarding the care of their children.

Nevertheless, it is also important to acknowledge that not all parents who experience neglect and abuse in childhood go on to repeat their past. From an attachment theory perspective, identifying and discussing childhood experiences is one means of breaking this cycle (Fraiberg et al., 1975). These strategies form an important component of attachmentbased therapy, such as the Circle of Security (Yaholkoski, Hurl, \& Theule, 2016). Similarly, as highlighted by Fraiberg et al. (1975), accessing the affective experiences of childhood memories and working through uncomfortable and sometimes painful affects with a therapist may assist in preventing the re-enactment of childhood experiences in the current parentchild relationship. This is further supported by research conducted by Barone et al. (2014), who found that the attachment styles most predictive of filicide perpetration by mothers were characterised by the inability to consciously reflect upon past experiences.

Consistent with attachment theory (Bowlby, 1973), the findings of the current study provide partial support for the continuity of attachment styles developed throughout a person's childhood, and imply that understanding of early attachment experiences may be useful in the treatment of mothers and fathers who come to the attention of health and social service providers displaying early warning signs such as difficulties bonding with their child(ren), low levels of social support, and mental health issues. We hope that the findings from this study will start a conversation about the merits of expanding or elaborating on attachment theory while taking into account gendered familial roles. 
ATTACHMENT STYLES AND FILICIDE BY GENDER

\section{References}

Ainsworth, M. D. (1978). Patterns of attachment: A psychological study of the strange situation. Lawrence Erlbaum Associates.

Ainsworth, M. S. (1979). Infant-mother attachment. American Psychologist, 34(10), 932937.

Ainsworth, M. S. (1989). Attachments beyond infancy. American Psychologist, 44(4), 709716.

Barone, L., Bramante, A., Lionetti, F., \& Pastore, M. (2014). Mothers who murdered their child: An attachment-based study on filicide. Child Abuse \& Neglect, 38(9), 1468-1477. http://dx.doi.org/10.1016/j.chiabu.2014.04.014

Benítez-Borrego S., Guàrdia-Olmos J., \& Aliaga-Moore Á. (2013). Child homicide by parents in Chile: A gender-based study and analysis of post-filicide attempted suicide. International Journal of Law and Psychiatry, 36(1), 55-64. https://doi.org/10.1016/j.ijlp.2012.11.008

Bourget, D., Grace, J., \& Whitehurst, L. (2007). A review of maternal and paternal filicide. Journal of the American Academy of Psychiatry and the Law, 35(1), 74-82.

Bowlby, J. (1973). Attachment and loss, Vol. 2: Separation: Anger and anxiety. Basic Books.

Brennan, K. A., Clark, C. L., \& Shaver, P. R. (1998). Self-report measurement of adult attachment: An integrative overview. In J. A. Simpson \& W. S. Rholes (Eds.), Attachment theory and close relationships (pp. 46-76). Guilford.

Bretherton, I. (1992). The origins of attachment theory: John Bowlby and Mary Ainsworth. Developmental Psychology, 28(5), 759-775.

Brookman, F., \& Nolan, J. (2006). The dark figure of infanticide in England and Wales: Complexities of diagnosis. Journal of Interpersonal Violence, 21(7), 869-889. https://doi.org/10.1177/0886260506288935 


\section{ATTACHMENT STYLES AND FILICIDE BY GENDER}

Brown, T., \& Tyson, D. (2014). Filicide: Recasting research and intervention. Child Abuse Review, 23(2), 75-78. https://doi.org/10.1002/car.2328

Caman, S., Howner, K., Kristiansson, M., \& Sturup, J. (2017). Differentiating intimate partner homicide from other homicide: A Swedish population-based study of perpetrator, victim, and incident characteristics. Psychology of Violence, 7(2), 306-315. https://doi.org/10.1037/vio0000059

Collins, N. L., \& Read, S. J. (1990). Adult attachment, working models, and relationship quality in dating couples. Journal of Personality \& Social Psychology, 58(4), 644-663. https://doi.org/10.1037/0022-3514.58.4.644

Cowan, P. A., \& Cowan, C. P. (2007). Attachment theory: Seven unresolved issues and questions for future research. Research in Human Development, 4(3-4), 181-201. https://doi.org/10.1080/15427600701663007

Crimmins, S., Langley, S., Brownstein, H. H., \& Spunt, B. J. (1997). Convicted women who have killed children: A self-psychology perspective. Journal of Interpersonal Violence, 12(1), 49-69. https://doit.org/10.1177/088626097012001004

Dobash, R. E., \& Dobash, R. (2015). When men murder women. Oxford University Press. https://doi.org/10.1093/acprof:oso/9780199914784.001.0001

Dutton, D. G. (2002). The neurobiology of abandonment homicide. Aggression and Violent Behavior, 7(4), 407-421. https://doi.org/10.1016/S1359-1789(01)00066-0

Eriksson, L., \& Mazerolle, P. (2015). A cycle of violence? Examining family-of-origin violence, attitudes, and intimate partner violence perpetration. Journal of Interpersonal Violence, 30(6), 945-964. https://doi.org/10.1177/0886260514539759

Eriksson, L., Mazerolle, P., Wortley, R., \& Johnson, H. (2016). Maternal and paternal filicide: Case studies from the Australian Homicide Project. Child Abuse Review, 25(1), 17-30. https://doi.org/10.1002/car.2358 


\section{ATTACHMENT STYLES AND FILICIDE BY GENDER}

Farooque, R. \& Ernst, F. (2003). Filicide: A view of eight years of clinical experinces. Journal of the National Medical Association, 95(1), 90-94.

Fraiberg, S., Adelson, E., \& Shapiro, V. (1975). Ghosts in the nursery: A psychoanalytic approach to the problems of impaired infant-mother relationships. Journal of the American Academy of Child Psychiatry, 14(3), 387-421. https://doi.org/10.1016/S00027138(09)61442-4

Genest, A.-A., \& Mathieu, C. (2014). Intimate partner violence: The role of attachment on men's anger. Partner Abuse, 5(4), 375-387. https://doi.org/10.1891/1946-6560.5.4.375

Haapasalo, J., \& Petäjä, S. (1999). Mothers who killed or attempted to kill their child: Life circumstances, childhood abuse, and types of killing. Violence and Victims, 14(3), 219239.

Harris Johnson, C. (2009). Intimate partner homicide and familicide in Western Australia. Domestic-related homicide: Keynote papers from the 2008 international conference on homicide (pp. 36-48). Australian Institude of Criminology.

https://www.aic.gov.au/publications/rpp/rpp104

Hazan, C., \& Shaver, P. (1987). Romantic love conceptualized as an attachment process. Journal of Personality \& Social Psychology, 52(3), 511-524. https://doi.org/10.1037/0022-3514.52.3.511

Identifying reference. Removed for purposes of peer-review.

Korbin, J. E. (1987). Incarcerated mothers' perceptions and interpretations of their fatally maltreated children. Child Abuse \& Neglect, 11(3), 397-407. https://doi.org/10.1016/0145-2134(87)90013-5

Liem, M., \& Koenraadt, F. (2008). Filicide: A comparative study of maternal versus paternal child homicide. Criminal Behaviour and Mental Health, 18(3), 166-176. https://doi.org/10.1002/cbm 


\section{ATTACHMENT STYLES AND FILICIDE BY GENDER}

Main M., \& Solomon J. (1986). Discovery of a new, insecure-disorganized/disoriented attachment pattern In M. Yogman \& T. B. Brazelton (Eds.), Affective development in infancy (pp. 95-124). Ablex Publishing.

Mathews, B., Pacella, R., Dunne, M. P., Simunovic, M., \& Marston, C. (2020). Improving measurement of child abuse and neglect: A systematic review and analysis of national prevalence studies. PLOS ONE, 15(1), Article e0227884.

https://doi.org/10.1371/journal.pone.0227884

McKee, A., \& Egan, V. (2013). A case series of twenty one maternal filicides in the UK. Child Abuse \& Neglect, 37(10), 753-761. https://doi.org/10.1016/j.chiabu.2013.02.008

Mugavin, M. (2008). Maternal filicide theoretical framework. Journal of Forensic Nursing, 4(2), 68-79. https://doi.org/10.1111/j.1939-3938.2008.00012.x

Raby, K. L., Steele, R. D., Carlson, E. A., \& Sroufe, L. A. (2015). Continuity and changes in infant attachment patterns across two generations. Attachment \& Human Development, 17(4), 414-428. https://doi.org/10.1080/14616734.2015.1067824

Ravitz, P., Maunder, R., Hunter, J., Sthankiya, B., \& Lancee, W. (2010). Adult attachment measures: A 25-year review. Journal of Psychosomatic Research, 69(4), 419-432. https://doi.org/10.1016/j.jpsychores.2009.08.006

Resnick, P. J. (1969). Child murder by parents: A psychiatric review of filicide. The American Journal of Psychiatry, 126(3), 325-334. https://doi.org/10.1176/ajp.126.3.325

Sachmann, M., \& Harris Johnson, C. M. (2014). The relevance of long-term antecedents in assessing the risk of familicide-suicide following separation. Child Abuse Review, 23(2), 130-141. https://doi.org/10.1002/car.2317

Sidebotham, P. (2013). Rethinking filicide. Child Abuse Review, 22(5), 305-310. https://doi.org/10.1002/car.2303

Stewart, C., Senger, M. M., Kallen, D., \& Scheurer, S. (1987). Family violence in stable 


\section{ATTACHMENT STYLES AND FILICIDE BY GENDER}

middle-class homes. Social Work, 32(4), 529-531. https://doi.org/10.1093/sw/32.6.529

Straus, M. A., \& Kantor, G. K. (2005). Definition and measurement of neglectful behavior: Some principles and guidelines. Child Abuse \& Neglect, 29(1), 19-29. https://doi.org/10.1016/j.chiabu.2004.08.005

Stroud, J. (2008). A psychosocial analysis of child homicide. Critical Social Policy, 28(4), 482-505. https://doi.org/10.1177/0261018308095281

van Ijzendoorn, M. H., Schuengel, C., \& Bakermans-Kranenburg, M. (1999). Disorganized attachment in early childhood: Meta-analysis of precursors, concomitants, and sequelae. Development and Psychopathology, 11(2), 225-49.

https://doi.org/10.1017/s0954579499002035

Vogel, D. L., \& Wei, M. (2005). Adult attachment and help-seeking intent: The mediating roles of psychological distress and perceived social support. Journal of Counseling Psychology, 52(3), 347-357. https://doi.org/10.1037/0022-0167.52.3.347

Wilczynski, A. (1997). Child homicide. Oxford University Press.

Yaholkoski, A., Hurl, K., \& Theule, J. (2016). Efficacy of the Circle of Security intervention: A meta-analysis. Journal of Infant, Child, and Adolescent Psychotherapy, 15(2), 95-103. https://doi.org/10.1080/15289168.2016.1163161

Yin, R. K. (2003). Case study research: Design and methods (3rd ed.). Sage. 
Table 1. Background factors, childhood experiences, and adult experiences among women $(\mathrm{n}=5)$ and men $(\mathrm{n}=13)$ who have committed filicide

Offender gender $\left(\mathrm{OG}^{*}\right)$, Offender relationship status $\left(\mathrm{RS}^{\wedge}\right), \quad$ Maternal $\left(\mathrm{MA}^{* *}\right)$ and

Familicide (F), Victim gender $\left(\mathrm{VG}^{*}\right)$, Relation to victim paternal $\left(\mathrm{PA}^{* *}\right)$ attachment

$\left(\mathrm{R}^{\#}\right)$, Other children in household $\left(\mathrm{OCH}^{\#}\right)$, Offender perpetrated child abuse previously (CA)
Childhood physical abuse (PA), Father-tomother violence (F-M), Mother-to-father

violence (M-F), Physical neglect (PN) and Emotional neglect (EN)
Adult romantic attachment (RA**),

social support (SS) and mental health $(\mathrm{MH})$

\begin{tabular}{|c|c|c|c|c|c|c|c|c|c|c|c|c|c|c|c|c|c|}
\hline$\#$ & OG & ORS & $\mathrm{F}$ & VG & $\mathrm{R}$ & $\mathrm{OCH}$ & $\mathrm{CA}$ & MA & PA & PA & F-M & M-F & PN & EN & RA & SS & $\mathrm{MH}$ \\
\hline 1 & $\mathrm{~F}$ & Mar & & $\mathrm{M}, \mathrm{F}$ & Gen & 0 & $\checkmark$ & Amb (I) & $\mathrm{Amb}(\mathrm{I})$ & & & & & $\checkmark$ & Pre (I) & & \\
\hline 2 & $\mathrm{~F}$ & Mar & & $\mathrm{F}$ & Gen & 0 & & $\operatorname{Sec}(\mathrm{S})$ & $\operatorname{Sec}(\mathrm{S})$ & & & & & $\checkmark$ & $\operatorname{Sec}(S)$ & & \\
\hline 3 & $\mathrm{~F}$ & Sep & & $\mathrm{F}$ & Gen & 0 & & $\operatorname{Sec}(\mathrm{S})$ & $\operatorname{Sec}(\mathrm{S})$ & & $\checkmark$ & & & & Dis (I) & $\checkmark$ & $\checkmark$ \\
\hline 4 & $\mathrm{~F}$ & Sin & & $\mathrm{M}$ & Gen & $1 x G e n$ & & $\operatorname{Sec}(\mathrm{S})$ & $\operatorname{Sec}(\mathrm{S})$ & & $\checkmark$ & & & & Dis (I) & & $\checkmark$ \\
\hline 5 & $\mathrm{~F}$ & Sep & & $\mathrm{F}$ & Gen & $2 \times \mathrm{Gen}$ & $\checkmark$ & Avoi (I) & Avoi (I) & & & & $\checkmark$ & $\checkmark$ & Pre (I) & & \\
\hline 6 & M & Mar & $\checkmark$ & $\mathrm{F}$ & Gen & 1xGen & $\checkmark$ & $\operatorname{Sec}(\mathrm{S})$ & Amb (I) & & $\checkmark$ & $\checkmark$ & $\checkmark$ & $\checkmark$ & Fear (I) & $\checkmark$ & \\
\hline 7 & M & $\mathrm{DF}$ & & M & Step & 0 & & $\mathrm{Sec} / \mathrm{Amb}(\mathrm{I})$ & $\operatorname{Abs}(\mathrm{A})$ & & & & & $\checkmark$ & Fear (I) & $\checkmark$ & \\
\hline 8 & M & DF & & $\mathrm{F}$ & Step & $3 x G e n$ & $\checkmark$ & $\operatorname{Sec}(\mathrm{S})$ & $\operatorname{Sec}(\mathrm{S})$ & $\checkmark$ & $\checkmark$ & & & $\checkmark$ & Dis ( $\mathrm{I})$ & & \\
\hline 9 & $\mathrm{M}$ & Mar & $\checkmark$ & $\mathrm{F}$ & Step & 2xGen;2xStep & $\checkmark$ & $\operatorname{Sec}(S)$ & $\operatorname{Abs}(\mathrm{A})$ & & & & & & $\operatorname{Sec}(S)$ & $\checkmark$ & \\
\hline 10 & M & $\mathrm{DF}$ & & M & Step & 1xGen;2xStep & $\checkmark$ & $\mathrm{Sec} / \mathrm{Amb}(\mathrm{I})$ & $\mathrm{Amb}(\mathrm{I})$ & $\checkmark$ & $\checkmark$ & & & $\checkmark$ & $\operatorname{Sec}(S)$ & & \\
\hline 11 & M & $\mathrm{DF}$ & & $\mathrm{F}$ & Gen & 2xStep & & $\mathrm{Amb}(\mathrm{I})$ & Avoi (I) & $\checkmark$ & $\checkmark$ & & $\checkmark$ & $\checkmark$ & Dis (I) & & \\
\hline 12 & $\mathrm{M}$ & DF & & $\mathrm{M}$ & Gen & $3 x G e n$ & $\checkmark$ & Amb (I) & Amb/Avoi (I) & $\checkmark$ & $\checkmark$ & & $\checkmark$ & $\checkmark$ & Pre (I) & & \\
\hline 13 & M & Sep & $\checkmark$ & $\mathrm{M}, \mathrm{M}$ & Step & 3xGen;1xStep & & $\operatorname{Sec}(\mathrm{S})$ & $\mathrm{Sec} / \mathrm{Amb}(\mathrm{I})$ & & & & & $\checkmark$ & Pre (I) & $\checkmark$ & \\
\hline 14 & $\mathrm{M}$ & $\mathrm{DF}$ & & $\mathrm{M}$ & Gen & 0 & $\checkmark$ & Amb/Avoi (I) & Avoi (I) & & & & $\checkmark$ & $\checkmark$ & Fear (I) & $\checkmark$ & \\
\hline 15 & M & Mar & & $\mathrm{F}$ & Step & $4 x G e n$ & $\checkmark$ & Avoi (I) & Abs (A) & & & & & $\checkmark$ & - & & \\
\hline 16 & $\mathrm{M}$ & Sep & $\checkmark$ & $\mathrm{F}$ & Step & $5 x G e n$ & & $\operatorname{Sec}(\mathrm{S})$ & $\operatorname{Sec}(\mathrm{S})$ & & & & $\checkmark$ & $\checkmark$ & - & & \\
\hline 17 & M & Mar & $\checkmark$ & $\mathrm{n} / \mathrm{a}$ & Gen & 0 & & Amb/Avoi (I) & $\operatorname{Sec}(S)$ & $\checkmark$ & $\checkmark$ & $\checkmark$ & $\checkmark$ & $\checkmark$ & $\operatorname{Sec}(S)$ & $\checkmark$ & \\
\hline 18 & M & Mar & & $\mathrm{M}$ & Step & 1xStep & $\checkmark$ & Amb (I) & Avoi (I) & $\checkmark$ & $\checkmark$ & & & $\checkmark$ & Fear (I) & & \\
\hline
\end{tabular}

Note: * $(\mathrm{M}=$ Male; $\mathrm{F}=$ Female), $\wedge$ (Mar = Married; Sep = Separated; Sin = Single; DF = De Facto), \# (Gen = Genetic kin; Step = Step-child), ** (Sec $=$ Secure, Amb = Anxious-

Ambivalent, Avoi = Avoidant, Pre = Preoccupied, Dis = Dismissing, Fear = Fearful, S = Secure, I = Insecure). Mixed attachment is represented by the combination of styles, e.g., AnxiousAmbivalent/Avoidant. 
Table 2. Self-reported attachment styles to primary caregivers and experiences of childhood abuse among individuals who have committed filicide and non-filicide homicide (valid \%)

\begin{tabular}{lcccc}
\hline & \multicolumn{2}{c}{ Filicide } & \multicolumn{2}{c}{$\begin{array}{c}\text { Non-filicide } \\
\text { homicide }\end{array}$} \\
\cline { 2 - 5 } \multicolumn{1}{c}{ Variable } & $\begin{array}{c}\text { Females } \\
(\mathrm{n}=5)\end{array}$ & $\begin{array}{c}\text { Males } \\
(\mathrm{n}=13)\end{array}$ & $\begin{array}{c}\text { Females } \\
(\mathrm{n}=35)\end{array}$ & $\begin{array}{c}\text { Males } \\
(\mathrm{n}=248)\end{array}$ \\
& $\mathrm{n}(\%)$ & $\mathrm{n}(\%)$ & $\mathrm{n}(\%)$ & $\mathrm{n}(\%)$ \\
\hline Attachment style to primary caregiver & & & & \\
Maternal - Secure & $3(60 \%)$ & $5(38 \%)$ & $16(52 \%)$ & $129(60 \%)$ \\
Paternal - Secure & $3(60 \%)$ & $3(23 \%)$ & $12(38 \%)$ & $88(41 \%)$ \\
Maternal - Insecure & $2(40 \%)$ & $8(62 \%)$ & $15(48 \%)$ & $75(35 \%)$ \\
Paternal - Insecure & $2(40 \%)$ & $7(54 \%)$ & $16(50 \%)$ & $98(46 \%)$ \\
Maternal - Absent & $0(0 \%)$ & $0(0 \%)$ & $0(0 \%)$ & $11(5 \%)$ \\
Paternal - Absent & $0(0 \%)$ & $3(23 \%)$ & $4(13 \%)$ & $29(14 \%)$ \\
Experiences of abuse in childhood & & & & \\
Physical abuse & $0(0 \%)$ & $6(46 \%)$ & $18(58 \%)$ & $138(60 \%)$ \\
Observed father-to-mother violence & $2(40 \%)$ & $7(54 \%)$ & $15(54 \%)$ & $89(44 \%)$ \\
Observed mother-to-father violence & $0(0 \%)$ & $2(15 \%)$ & $3(11 \%)$ & $39(19 \%)$ \\
Physical neglect & $1(20 \%)$ & $6(46 \%)$ & $12(38 \%)$ & $77(34 \%)$ \\
Emotional neglect & $3(60 \%)$ & $12(92 \%)$ & $24(75 \%)$ & $120(54 \%)$ \\
\hline
\end{tabular}


Table 3. Overlap between childhood experiences of abuse and neglect, perpetration of child abuse in adulthood, and attachment style in childhood among women and men who have committed filicide and non-filicide homicide (valid \%)

\begin{tabular}{|c|c|c|c|c|c|c|c|c|}
\hline \multirow[b]{3}{*}{ Variable } & \multicolumn{4}{|c|}{ Filicide } & \multicolumn{4}{|c|}{ Non-filicide homicide } \\
\hline & \multicolumn{2}{|c|}{$\begin{array}{c}\text { Females } \\
\quad(n=5)\end{array}$} & \multicolumn{2}{|c|}{$\begin{array}{l}\text { Males } \\
(\mathrm{n}=13)\end{array}$} & \multicolumn{2}{|c|}{$\begin{array}{l}\text { Females } \\
(\mathrm{n}=35)\end{array}$} & \multicolumn{2}{|c|}{$\begin{array}{c}\text { Males } \\
(\mathrm{n}=248)\end{array}$} \\
\hline & $\begin{array}{l}\text { Secure } \\
\mathrm{n}(\%)\end{array}$ & $\begin{array}{c}\text { Insecure } \\
\mathrm{n}(\%)\end{array}$ & $\begin{array}{l}\text { Secure } \\
\mathrm{n}(\%)\end{array}$ & $\begin{array}{c}\text { Insecure } \\
\mathrm{n}(\%)\end{array}$ & $\begin{array}{l}\text { Secure } \\
\mathrm{n}(\%)\end{array}$ & $\begin{array}{c}\text { Insecure } \\
\mathrm{n}(\%)\end{array}$ & $\begin{array}{c}\text { Secure } \\
\mathrm{n}(\%)\end{array}$ & $\begin{array}{c}\text { Insecure } \\
\mathrm{n}(\%)\end{array}$ \\
\hline \multicolumn{9}{|c|}{ Experienced abuse in childhood* } \\
\hline Yes & $2(67 \%)$ & $0(0 \%)$ & $1(33 \%)$ & $6(60 \%)$ & $5(56 \%)$ & $17(77 \%)$ & $31(45 \%)$ & $111(87 \%)$ \\
\hline No & $1(33 \%)$ & $2(100 \%)$ & $2(67 \%)$ & $4(40 \%)$ & $4(44 \%)$ & $5(23 \%)$ & $38(55 \%)$ & $16(13 \%)$ \\
\hline \multicolumn{9}{|c|}{ Experienced neglect in childhood } \\
\hline Yes & $1(33 \%)$ & $2(100 \%)$ & $2(67 \%)$ & $10(100 \%)$ & $5(50 \%)$ & $19(86 \%)$ & $12(16 \%)$ & $99(77 \%)$ \\
\hline No & $2(67 \%)$ & $0(0 \%)$ & $1(33 \%)$ & $0(0 \%)$ & $5(50 \%)$ & $3(14 \%)$ & $62(84 \%)$ & $30(23 \%)$ \\
\hline \multicolumn{9}{|c|}{ Perpetrated child abuse in adulthood } \\
\hline Yes & $0(0 \%)$ & $2(100 \%)$ & $2(67 \%)$ & $6(60 \%)$ & $1(11 \%)$ & $6(32 \%)$ & $14(23 \%)$ & $14(12 \%)$ \\
\hline No & $3(100 \%)$ & $0(0 \%)$ & $1(33 \%)$ & $4(40 \%)$ & $8(89 \%)$ & $13(68 \%)$ & $46(77 \%)$ & $103(88 \%)$ \\
\hline
\end{tabular}

Note. Percentages may not total 100 due to rounding. Secure $=$ secure attachment to both caregivers, or one caregiver secure and the other absent. Insecure $=$ at least one caregiver insecure. Abuse in childhood = experienced direct physical abuse and/or observed parental violence. Neglect in childhood $=$ experienced physical and/or emotional neglect. 
Table 4. Self-reported adult romantic attachment style, continuity of attachment pattern from childhood (to primary caregivers) to adulthood (to romantic partner), and access to social support and mental health treatment/assessment in adulthood among women and men who have committed filicide and non-filicide homicide (valid \%)

\begin{tabular}{lcccc} 
& \multicolumn{2}{c}{ Filicide } & Non-filicide homicide \\
\cline { 2 - 5 } \multicolumn{1}{c}{ Variable } & $\begin{array}{c}\text { Females } \\
(\mathrm{n}=5)\end{array}$ & $\begin{array}{c}\text { Males } \\
(\mathrm{n}=13)\end{array}$ & $\begin{array}{c}\text { Females } \\
(\mathrm{n}=35)\end{array}$ & $\begin{array}{c}\text { Males } \\
(\mathrm{n}=248)\end{array}$ \\
& $\mathrm{n}(\%)$ & $\mathrm{n}(\%)$ & $\mathrm{n}(\%)$ & $\mathrm{n}(\%)$ \\
\hline Romantic attachment style (adulthood) & & & & \\
Secure & $1(20 \%)$ & $3(27 \%)$ & $5(17 \%)$ & $60(31 \%)$ \\
Insecure - Preoccupied & $2(40 \%)$ & $2(18 \%)$ & $12(41 \%)$ & $61(31 \%)$ \\
Insecure - Dismissing & $2(40 \%)$ & $2(18 \%)$ & $7(24 \%)$ & $40(20 \%)$ \\
Insecure - Fearful & $0(0 \%)$ & $4(36 \%)$ & $5(17 \%)$ & $35(20 \%)$ \\
Attachment continuity (childhood $\rightarrow$ adulthood)* & & & & \\
Secure child $\rightarrow$ Secure adult & $1(20 \%)$ & $2(18 \%)$ & $3(10 \%)$ & $23(13 \%)$ \\
Secure child $\rightarrow$ Insecure adult & $2(40 \%)$ & $2(18 \%)$ & $6(21 \%)$ & $43(23 \%)$ \\
Insecure child $\rightarrow$ Insecure adult & $2(40 \%)$ & $6(55 \%)$ & $18(62 \%)$ & $82(45 \%)$ \\
Insecure child $\rightarrow$ Secure adult & $0(0 \%)$ & $1(9 \%)$ & $2(7 \%)$ & $35(19 \%)$ \\
Perceived access to social support (adulthood) & $1(20 \%)$ & $6(46 \%)$ & $11(32 \%)$ & $106(47 \%)$ \\
Mental health treatment/assessment (adulthood) & $2(40 \%)$ & $0(0 \%)$ & $8(25 \%)$ & $43(19 \%)$ \\
\hline
\end{tabular}

* "Secure" child attachment style $=$ respondents who reported secure attachment to at least one caregiver.

${ }^{\mathrm{i}}$ For further information about the study and its findings, the reader is referred to the study website (identifying reference). 